\title{
Temporal versus Superior Limbal Incision: Any difference in visual outcome? Initial report of 40 retrospective cases
}

\author{
CN Pedro-Egbe MB;BS, FMCOph, Bassey Fiebai MB;BS. FMCOph \\ Department of Ophthalmology, University of Port Harcourt Teaching Hospital, Port Harcourt, Nigeria
}

\section{ABSTRACT}

Aim: To compare the visual outcome of a superiorly placed limbal incision with a temporal limbal incision in extracapsular cataract surgery. The main outcome measures are visual acuity and the degree of stigmatism based on refraction.

Method: A retrospective non randomized comparative study. Medical records of 40 patients (40 eyes) who had uni-ocular extra-capsular cataract extraction over a 6month period were used for the study. Relevant data extracted included age and sex, presenting visual acuity, type of incision used for cataract extraction, visual acuity, and refraction results at the $13^{\text {th }}$ postoperative week. The exclusion criteria were any visible ocular condition that could affect visual acuity such as corneal scar, glaucoma or vitreous loss.

Results: A total of 40 cases were studied; 22 (55\%) males and 18 (45\%) females. About 65\% (26) were aged 50-89 years; mean 50.12 years $(\mathrm{SD}=23.28)$. Twenty six patients $(65 \%)$ had temporal limbal incision while 14 had superior limbal incision. Of these. $76.9 \%$ of the temporal limbal incision group had VAs of $6 / 18$ or better 6 weeks after surgery, compared to $64.3 \%$ for the superior limbal incision group (table 5). This difference was statistically significant $(\mathrm{P}=0.01)$. At the $13^{\text {th }}$ postoperative week, 20 eyes $(76.9 \%)$ had corrected visual acuities of $6 / 12$ or better for the temporal incision group, and 6 eyes $(42.9 \%)$ in the superior limbal incision group (table 6). This difference was however not statistically significant $(\mathrm{P}=0.07)$.

Most eyes (76.2\%) in the temporal incision group had between 0.25DC-2.00DC of astigmatism compared to $46.2 \%$ in the superior limbal incision group who also had higher degrees of astigmatism (53.8\%). This finding was however not statistically significant $(P=0.15)$

Conclusion: Temporal limbal incision has been shown to have a better visual outcome at 6 weeks postoperative $(p=0.01)$ and a lower level of astigmatism compared to superior limbal incision at 13 weeks postoperative.

Key words: ECCE: temporal versus superior incision

\section{INTRODUCTION}

Though cataract extraction is the most common surgery performed in ophthalmology, the visual outcome is sometimes disappointing. Many factors can affect visual outcome, including the direction and location of the wound which is said to have a significant impact on surgical outcome. ${ }^{1}$ Cataract surgery can be performed through clear corneal, limbal or scleral incisions, which can be placed in either the superior or temporal meridian. For clear corneal incisions, it has been reported that temporal incisions induce less astigmatism than superior ${ }^{2-5}$ and superolateral incisions. ${ }^{6}$ It has also been reported that high astigmatism is an important cause of poor uncorrected visual acuity after cataract surgery. ${ }^{7,8}$ Temporal incisions have also been found to give a more stable postoperative wound 6 weeks after surgery. ${ }^{9}$

\section{MATERIALS AND METHODS}

The medical records of 40 patients (22 males and 18 females) aged $6-86$ years $($ mean $=50.12$ years; $S D=23.28)$ who had uni-ocular extra-capsular cataract extraction over a 6-month period were included in the study. Relevant data extracted included age and sex, presenting visual acuity, type of incision used for cataract extraction, visual acuity at 6 and 13 weeks and refraction results at the $13^{\text {th }}$ postoperative week.

The exclusion criteria were any visible ocular condition that could affect visual acuity such as corneal scar, glaucoma, previous ocular surgery or trauma. Those with vitreous loss were also excluded from the study. All the surgeries were performed by the principal author and assisted by the co-author.

Preoperatively, all patients had corrected visual acuity measurement, slit-lamp examination of the anterior and posterior segments, and biometry, using the IOL Master (Zeiss Humphrey Acuitus 5015). All surgeries were performed under topical amethocaine and peri-bulbar anaesthesia using a combination of xylocaine $0.5 \%$ and bupivacaine $0.5 \%$ in a ratio of $3: 2$. Fourteen patients had superior limbal incisions placed between the 10 and 2 o'clock positions while 26 had temporal limbal incisions placed between the 7 and 11 o'clock positions. A stab incision was

${ }^{*}$ Correspondence: Chinyere Nnenne Pedro-Egbe, Department of Ophthalmology, University of Port Harcourt Teaching Hospital, Port Harcourt, Nigeria •e-mail: cpegbe@weltekng.com 
made into the anterior chamber after which visco-elastic material was injected and a can-opener capsulotomy done. The lens nucleus was delivered using a vectis loop and a squint hook. Cortical matter was washed out by irrigation and aspiration using Simcoe cannula. A posterior chamber intraocular lens (IOL) was implanted in the capsular bag. The corneo-scleral wound was closed with 10-0 nylon sutures (5 interrupted sutures).

Postoperatively, all patients received topical spersadexcompound and chloramphenicol eye drops 2 hourly for one week and then 6 hourly for the next 6 weeks. They also had voltaren eye drops 6 hourly for 6 weeks, mydriacyl drops thrice daily for 4 weeks and chloramphenicol ointment at night.

Visual acuity (using Snellen's chart) was assessed at 6 weeks and refraction carried out at 13 weeks by a single optometrist using streak retinoscopy (Welch Allyn USA model 18200). Astigmatism was defined based on refraction results and data was analysed using Edi-info Version 6.04.

\section{RESULTS}

Postoperatively, no significant complication (such as posterior capsule rupture or vitreous loss) was recorded in the 40 eyes. All 40 patients had their final refraction at 13 weeks postoperative.

Of the 40 cases studied, 22 (55\%) were males and 18 $(45 \%)$ were females. More of the patients $(65 \%)$ were aged $50-89$ years $($ mean $=50.12$ years, $S D=23.28$. About a third $(35 \%)$ of the patients were less than 50 years old (table 1$)$.

Table 1. Age and sex distribution of patients

\begin{tabular}{cccl}
\hline $\begin{array}{c}\text { Age Group } \\
(\text { Years })\end{array}$ & Male & Female & $\begin{array}{c}\text { Total } \\
(\%)\end{array}$ \\
\cline { 2 - 3 } $0-9$ & 2 & - & $2(5 \%)$ \\
$10-19$ & 2 & 4 & $6(15 \%)$ \\
$20-29$ & - & - & $-(0 \%)$ \\
$30-39$ & 4 & - & $4(10 \%)$ \\
$40-49$ & - & 2 & $2(5 \%)$ \\
$50-59$ & 4 & 3 & $7(17.5 \%)$ \\
$60-69$ & 6 & 3 & $9(22.5 \%)$ \\
$70-79$ & 4 & 4 & $8(20 \%)$ \\
$80-89$ & - & 2 & $2(5 \%)$ \\
\hline Total & $22(55 \%)$ & $18(45 \%)$ & $40(100 \%)$ \\
\hline
\end{tabular}

Most patients (85\%) had presenting visual acuity (VA) of counting finger (CF) to light perception (LP). Only 6 persons $(15 \%)$ had VA of $6 / 36$ (table 2 ).

Table 2. Presenting visual acuity of study subjects

\begin{tabular}{lccccccc}
\hline $\begin{array}{l}\text { Visual } \\
\text { Acuity }\end{array}$ & $6 / 36$ & $6 / 60$ & $3 / 60$ & CF & HM & LP & Total \\
\hline RE(No) & 4 & - & - & 8 & 4 & 6 & 22 \\
& & & & & & & \\
LE(No) & 2 & - & - & 4 & 6 & 6 & 18 \\
Total & 6 & 0 & 0 & 12 & 10 & 12 & 40 \\
& $(15 \%)$ & $(0 \%)$ & $(0 \%)$ & $(30 \%)$ & $(25 \%)$ & $(30 \%)$ & $(100 \%)$ \\
\hline
\end{tabular}

At 6 weeks postoperative, 28 eyes $(70.0 \%)$ had VA of 6/6- 6/18, which improved to $87.5 \%$ at 13 weeks; 6 eyes had VA of $6 / 24$, while two eyes had VA of $6 / 60$ (table 3).

At the $13^{\text {th }}$ postoperative week, 19 eyes (47.5\%) had corrected VA of $6 / 9$ or better and 14 eyes (35\%) VA of $6 / 12$ $6 / 18$. Only two eyes had VA of 6/60 (table 4).

Twenty-six patients (65\%) had temporal limbal incision while 14 patients had superior limbal incision. Of the temporal limbal incision group $76.9 \%$ had VA of $6 / 18$ or better at 6 weeks compared to $64.3 \%$ for the superior limbal incision group (table 5). This difference was statistically significant $(\mathrm{P}=0.01)$. Six patients with temporal incision attained a visual acuity of $6 / 6$ at 6 weeks postoperative.

At 13 weeks postoperative, 20 eyes $(76.9 \%)$ had corrected VA of $6 / 12$ or better for the temporal incision group compared to 6 eyes $(42.9 \%)$ in superior limbal incision group (table 6). This difference was however not statistically significant $(\mathrm{P}=0.07)$.

A total of 34 eyes $(85 \%)$ had postoperative astigmatism (table 7). The remaining nine eyes were corrected by spherical lenses alone. Most eyes (76.2\%) in the temporal incision group had between 0.25DC-2.00DC astigmatism compared to $46.2 \%$ in the superior limbal incision group. The superior incision group also had higher degrees of astigmatism $(53.8 \%)$ compared to the temporal incision group $(23.8 \%)$. This finding was also not statistically significant $(\mathrm{p}=0.15)$

Table 3. Visual acuity 6 weeks postoperative

\begin{tabular}{|c|c|c|c|c|c|c|c|c|}
\hline Visual Acuity & $6 / 6$ & $6 / 9$ & $6 / 12$ & $6 / 18$ & $6 / 24$ & $6 / 36$ & $6 / 60$ & Total \\
\hline $\mathrm{RE}(\mathrm{No})$ & 2 & 2 & 4 & 4 & 4 & 4 & 2 & 22 \\
\hline $\mathrm{LE}(\mathrm{No})$ & 4 & 2 & 6 & 4 & 2 & - & - & 18 \\
\hline Total & $6(15 \%)$ & $4(10 \%)$ & $10(25 \%)$ & $8(20 \%)$ & $6(15 \%)$ & $4(10 \%)$ & $2(5 \%)$ & $40(100 \%)$ \\
\hline
\end{tabular}


Table 4. Corrected visual acuity at 13 weeks postoperative

\begin{tabular}{llllllll}
\hline Visual Acuity & $6 / 6$ & $6 / 9$ & $6 / 12$ & $6 / 18$ & $6 / 24$ & $6 / 36$ & $6 / 60$ \\
\hline RE(No) & 6 & 4 & 2 & 4 & 2 & 2 \\
LE(No) & 4 & 5 & 4 & 4 & 1 & - & - \\
\hline Total & $10(25 \%)$ & $9(22.5 \%)$ & $6(15 \%)$ & $8(20 \%)$ & $3(7.5 \%)$ & $2(5 \%)$ & $2(5 \%)$ \\
\hline
\end{tabular}

Table 5. Type of incision and visual acuity at 6 weeks postoperative

\begin{tabular}{|c|c|c|c|c|c|c|c|c|}
\hline Visual Acuity & $6 / 6$ & $6 / 9$ & $6 / 12$ & $6 / 18$ & $6 / 24$ & $6 / 36$ & $6 / 60$ & Total \\
\hline \multicolumn{9}{|c|}{ Superior Limbal } \\
\hline Incision & - & 2 & 4 & 3 & 1 & 2 & 2 & 14 \\
\hline \multicolumn{9}{|c|}{ Temporal Limbal } \\
\hline Incision & 6 & 2 & 7 & 5 & 2 & 4 & - & 26 \\
\hline Total & $6(15 \%)$ & $4(10 \%)$ & $11(22.5 \%)$ & $8(20 \%)$ & $3(7.5 \%)$ & $6(15 \%)$ & $2(5 \%)$ & $40(100 \%)$ \\
\hline
\end{tabular}

Table 6. Type of incision and corrected visual acuity at 13 weeks postoperative

\begin{tabular}{llllllll}
\hline Visual Acuity & $6 / 6$ & $6 / 9$ & $6 / 12$ & $6 / 18$ & $6 / 24$ & $6 / 36$ & $6 / 60$ \\
\hline $\begin{array}{l}\text { Superior Limbal } \\
\text { Incision }\end{array}$ & $1(7.1 \%)$ & $3(21.4 \%)$ & $2(14.3 \%)$ & $4(28.6 \%)$ & $4(28.6 \%)$ & - & - \\
$\begin{array}{l}\text { Temporal Limbal } \\
\text { Incision }\end{array}$ & & & & & & & \\
& $6(23.1 \%)$ & $8(30.8 \%)$ & $6(23.1 \%)$ & $5(19.2 \%)$ & $1(3.8 \%)$ & - & - \\
\hline & 7 & 11 & 8 & 9 & $400 \%)$ \\
\hline
\end{tabular}

Chi Square $=3.27(\mathrm{P}=0.07)$

Table 7. Type of incision and degree of astigmatism at 13 weeks postoperative

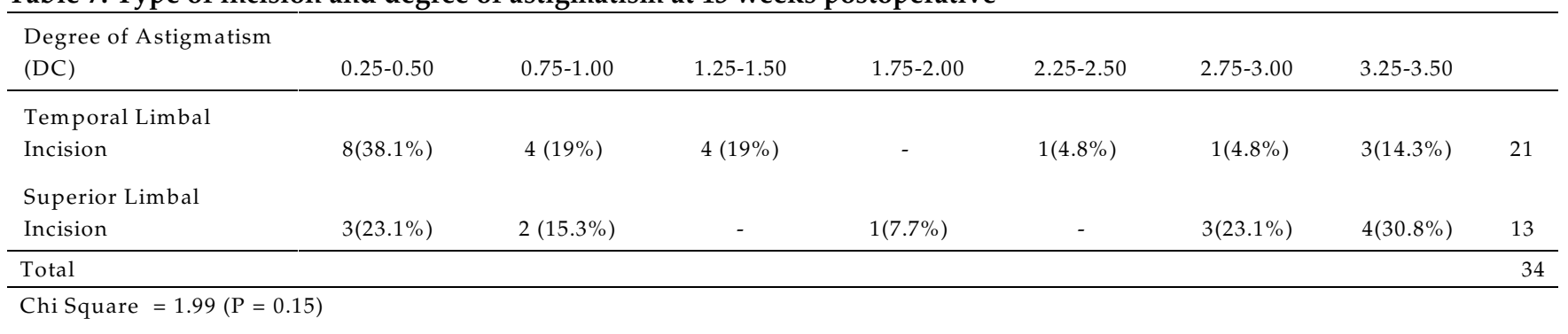

\section{DISCUSSION}

Cataract extraction is the most common surgery performed in ophthalmology and as such the various surgical procedures are constantly being improved to achieve better visual outcome. For a long time, standard procedure utilized superiorly placed clear corneal or limbal incisions, until recently when temporal incisions were introduced. Temporal incisions have been found to induce less astigmatic changes than superior incisions ${ }^{1,5,10}$ of identical length placed at the same distance from the limbus. ${ }^{1}$ This agrees with the findings in the present study and could be because most elderly cataract patients have preoperative against-the-rule astigmatism which may be neutralized by with-the-rule astigmatism induced by a temporal incision. ${ }^{10}$ Compared to other studies, our study utilized both visual acuity and degree of astigmatism (based on refraction) as the main outcome measures. ${ }^{11,12}$
At the $13^{\text {th }}$ week postoperative, more eyes $(76.9 \%)$ in the temporal incision group had better corrected visual acuity (6/12 or better) compared to $42.9 \%$ for the superior limbal incision group. The difference was however not statistically significant $(\mathrm{P}=0.07)$ probably because of the small sample size. Of the five eyes with corrected visual acuities less than $6 / 18$ at 13 weeks; four had superior incision and one, temporal incision. Two eyes had end-stage glaucoma, another two had age-related macular degeneration, and for the last eye, no apparent cause was immediately seen.

Our study also showed that eyes that had temporal incision had lesser degrees of astigmatism compared to those with superior incisions. This finding was however not statistically significant $(\mathrm{p}=0.15)$ probably because of the wide disparity in sample size between the two groups; one being 26 and the other 14 . 
But the result is in keeping with findings from other studies $^{1,10}$ where similar results were obtained, though the surgical procedures were different, being manual small incision cataract surgery in the first study ${ }^{1}$ and phacoemulsification in the second study. ${ }^{10}$ Some reasons have already been advanced for the better visual outcome; one of which is that the temporal location is farthest from the visual axis and any flattening due to the wound is less likely to affect the corneal curvature at the visual axis, ${ }^{10}$ compared to an incision that is located superiorly, where both gravity and eyelid blink tend to create a drag on the incision. ${ }^{10}$ These forces are also said to be neutralized better with temporally placed incisions because the incision is parallel to the vector of the forces. ${ }^{10}$

In conclusion, temporal limbal incision has been shown to have a better visual outcome at 6 weeks postoperative $(p=0.01)$ and a lower level of astigmatism compared to superior limbal incision at 13 weeks postoperative. This study is however limited by the fact that no preoperative refractions were done to compare with the postoperative refractive results and the number studied was too small to draw far-reaching conclusions. Further studies using a larger sample size need to be carried out to validate this result.

\section{REFERENCES}

1. Madhavi Madhu G, Raju VK. A study on postoperative corneal astigmatism in superior and temporal sections of scleral pocket small incision cataract surgery. AIOC 2006 Proceedings.

2. Roman SJ, Auclin FX, Chong-Sit DA, Ullern MM. Surgically induced astigmatism with superior and temporal incisions in cases of with-the-rule preoperative astigmatism. J Cataract Refract Surg 1998; 24: 1636-1641.

3. Joo CK, Han HK, Kim JH. Computer assisted videokeratography to measure changes in astigmatism induced by suture less cataract surgery. J Cataract Refract Surg 1997; 23: 555-561.

4. Simsek S, Yasar T, Demirok A, Cinal A, Yilmaz O F. Effect of superior and temporal clear corneal incisions on astigmatism after suture less phacoemulsification. $J$ Cataract Refract Surg 1998; 24: 515-518.

5. Goes FM Jr, Goes FJ. Astigmatic changes after suture less a small-incision cataract-surgery using a superior or temporal corneal incision. Bull Soc Belge Ophthalmol 1998; 268: 27-32.

6. Rainer G, Menapace R, Vass C, Schulz H. Corneal shape changes after temporal and superolateral $3.0 \mathrm{~mm}$ clear corneal incisions. J Cataract Refract Surg 1999; 25: 11211126.

7. Prajna NV, Chandrakanth KS, Kim R, Narendran V, Selvakumar S, Rohini G, et al . The Madurai intraocular lens study II: clinical outcomes. Am J Ophthalmol 1998;125: 14-25.

8. Yorston D, Foster A, Wood M, Foster A. Does prospective monitoring improve cataract surgery outcomes in Africa? Br J Ophthalmol 2002;86: 543-547.

9. Kohnen T, Mann PM, Husain SE, Abarca A, Koch DD. Corneal topographic changes and induced astigmatism resulting from superior and temporal sclera pocket incisions. Ophthalmic Surg Lasers 1996; 27: 263-269.

10. Gokhale NS, Sawhney S. Reduction in astigmatism I manual small incision cataract surgery through change of incision site. Indian J Ophthalmol 2005; 53: 201-203

11. Cravy TV. Routine use of lateral approach to cataract extraction to achieve rapid and sustained stabilization of postoperative astigmatism. J Cataract Refract Surg 1991;17: 415-423.

12. Axt JC, Mc Caffery JM. Reduction of postoperative against-the-rule astigmatism by lateral incision technique. J Cataract Refract Surg 1993; 19: 380-386. 